\title{
Publicações Recebidas
}

Apresentamos o seguinte rol de publicações a nós enviadas, cuja remessa, agradecemos.

Administração Paulista - Revista do Serviço Público. É publicada pelo Departamento Estadual de Administração (DEA) do Estado de São Paulo, no Brasil. Temos em mãos - volume 8 referente ao periodo de Julho/Dezembro de 1964, que começa com a biografia de vários homens públicos brasileiros que fo. ram governadores no Estado de São Paulo, sob o título «Chefes do Govêrno Paulista». Desta feita, detevese a parte desta revista incumbida dêsse registro, na biografia de Interventores Estaduais do periodo de $1930 / 32$, iniciando-se, esta, com o lapso de tempo de governança exercido pelo Interventor Federal João Alberto Lins de Barros, que abrangeu os periodos de $30-10-930$ a 25 de novembro de 1930 , como Delegado Militar, e de 25-11-930 a 24 de julho de 1931, como Interventor Federal, naquele Estado brasileiro. A mesma publicação apresenta ainda, diversos artigos a respeito de administração pública, e comentários sôbre livros e revistas, dentre os quais é comentada esta nossa revista, cujo título é idêntico ao daquela. Aparece aí, também matéria atinente às Secretarias de Estado dessa unidade da nossa Federação. inclusive, legislação e jurisprudência.

Américas - Esta revista é publicada mensalmente em português, inglês e espanhol, pela Divisão de Relações Culturais das Nações Unidas, sob os auspícios da União Pan-americana, possuindo também, no Brasil. caixa postal com número 1980 ZC-00 - Rio de Janeiro, Gb. De- dica-se a divulgar, minudentemente, noticias das diversas organizações norte-americanas, de que fazem parte paises dos continentes americanos. Chegado a esta redação, presentemente, o $\mathrm{n}^{\circ}$ XVII volume 5 , de maio de 1965 , proveniente de Washington, 6, D. C.

Anales - Esta publicação é oriunda da «Universidad Central del Ecuador», e conosco, presentemente, o Tomo XCIV - $\mathrm{n}^{\circ}$ 349. A presente revista edita, com exclusividade, assuntos estudantis, sendo impressa em Quito, capital do Equador.

Annual Report of the Secretary - General on the work of the organization. O volume 16 - June, 1964 - 15 June, 1965 - Supplement $\mathrm{n}^{2} 1(\mathrm{~A} / 6001)$, contém os Atos Oficiais da $20^{*}$ Sessão.

Boletim da Contadoria Geral da Republica - Este boletim é o órgão oficial da C.G.R. do Brasil. No editorial de $\mathrm{n}^{2} 335 / 7$ - Ano XL - de Outubro/Novembro/Dezembro de 1964 , o assunto ali debatido e «Reforma Tributária», cuidando êle, em seu conteúdo, das alterações havidas no âmbito tributário fiscal, enviadas pelo Poder Executivo ao Congresso, e transformadas em leis pelo mesmo. Fala o mesmo editorial, da criação no $\mathrm{Mi}$ nistério da Fazenda, do Departamento de Arrecadação e do Serviço de Processamento de Dados, incluindo, outrossim, a instituição do Cadastro Federal das Pessoas Jurídicas e a reorganização da Diretor'a das Rendas Internas.

Boletim Informativo - do Serviço Social da Indústria (SESI). Editado pela Divisão de Intercâmbio e As- 
sistência Técnica do Departamento Nacional do Serviço Social da Indústria, o presente boletim de $\mathrm{n}^{\circ} 3$ do Ano X, apresenta dados colhidos no periodo de 1 de junho a 30 do mesmo mês, do corrente ano. E impresso no Estado da Guanabara, no Brasil.

Boletim Técnico - da Secretaria de Viação e Obras Públicas. Trata o presente boletim, de assuntos ligados aos problemas de transportes, de obras públicas, de fundações de estruturas, construções de açudes, comunicações, energia elétrica, pavimentação de estradas, pontes, canais, aquedutos e ferrovias, em artigos assinados por diversos engenheiros. E originário êste boletim, de Recife, capital do Estado de Pernambuco, no Brasil, e nossa redação recebeu do Ano XXVII dessa publicação, os volumes LXXVI e LXXVII de Janeiro a Junho de 1965, num só exemplar.

Bulletin Analytique de Documentation Politique, Economique et Sociale Contemporaine - Boletins referentes ao $20^{\circ}$ ano - de ns. 3 e 4 , ambos de 1965, editados em Paris, França. Nêles são dados os nomes dos artigos e a variedade dos temas mencionados em cada exemplar, pelo realce do assunto veiculado nas publicações de onde foram extraidos, em face da direção dêsse boletim, julgá-los merecedores de destaque. Assinalam êles a matéria que lhes pareça essencialmente original e importante. No de $\mathrm{n}^{2} 3$. estão registradas as revistas chegadas à redação do mesmo, até o mês de março; no de $\mathrm{n}^{2} 4$, aquelas recebidas em abril do corrente ano.

Brasil Açucareiro - Orgão oficial do Instituto do Açucar e do Alcool, esta publicação, apresenta, sempre, abrindo seus volumes, um artigo fundamentado no tema que constitui a finalidade do órgão que a ećita, que é a de cuidar da agroindústria da cana de açucar e do alcool. Intitula-se êste, comumente, Notas e Comentários. Temos em mãos, os seguintes exemplares: Ano XXXIII - $\mathrm{N}^{\circ} 5$ - LXV - Maio de 1965; $\mathrm{N}^{\circ} 6$ - LXV - Junho de 1965; No 1 - LXVI - Julho de $1965-\mathrm{N}^{\circ} 2$ - LXVI Agôsto de 1965, do Serviço de Documentação do citado Instituto. No exemplar referente ao mês de Junho, êste editorial chama-se «Esperanças no Amanhã», e no de Maio. denomina-se «Primeiro Aniversário».

Carta Mensal - Esta revista, que é o órgão publicitário do Conselho Técnico da Confederação Nacional do Comércio e da Administração Nacional do Serviço Especial do Comércio, é editada pela Divisão de Divulgação da Confederação Nacional do Comércio. Carta Mensal destina-se a publicar as conferências pronunciadas nas reuniões semanais do mencionado Conselho. Foram-nos enviadas, recentemente. os volumes de ns. respectivos: 122 . de Maio de 1965; e 124, de Julho de 1965, ambos do Ano XI dessa publicação.

Cemento Portland - Esta revista tem a finalidade de aperfeiçoar e difundir o uso do Cimento Portland. O presente volume de $n^{\circ} 58$, de junho de 1965, editado em Buenos Aires. na Argentina, faz referência aos 25 anos de existência do referido Instituto, e, no editorial que é dedicado ao registro desta data, explicam ser essa instituição, uma entidade de utilidade pública, embora sem fins de lucro apesar de ser a mesma sustentada por emprêsas da indústria privada, produtoras de cimento. Cita o referido editorial, que êsse órgão se reveste de caracteristicas singulares, pois, funciona como entidade assessôra e consultiva, a respeito de problemas técnicos ligados a essa indústria.

C'ub Municipal - Esta publicaçã̃o é o órgão oficial de propriedade da classe de funcionários estaduais do Estado da Guanabara. Nela são transmitidas as noticias de interêsse geral para o funcionalismo daquela região do pais, e também, aquelas referentes ao dito órgão.

Conosco, atualmente, o de ns. 297. 8-9 - Julho/Agôsto/Setembro de 1965 - Estado da Guanabara. Brasil. 
Cuadernos Bibliotecológicos - Estes boletins são editados pela Secretaria Geral de Organização da $\mathrm{OEA}$, à qual se subordina o Departamento de Assuntos Culturais que se integra também, da Biblioteca Colón, em Washington 6, D.C. O presente boletim, de $\mathrm{n}^{0} 24$, do mês de Junho do corrente ano, é apresentado em espanhol, e vem aberto pelo seguinte artigo: Encabezamientos de matéria para la América Latina, de autoria da Marietta $\mathrm{Da}$ niels Shepard, que é Chefe do Programa de Fomento de Bibliotecas da União Pan-americana. São êstes folhetos de distribuição limitada, e cuidam de assuntos genéricos de biblioteconomia.

O Cultivador - Órgão oficial informativo, agricola e cultural do $\mathrm{Co}$ légio Agricola de Santa Teresa. Dêste jornal, recebemos o de ns. 217/8 - Ano XVIII - Julho/ Agôsto de 1965, que informa em seu-editorial, quais foram os resultadios obtidos durante a $19^{a}$ Semana do Lavrador, realizada naquele Colégio, no periodo de 28 a 31 de junho dêste ano, na c'dade de São João de Petrópolis, no Estado Brasileiro do Espirito Santo.

Diário Oficial do Estado de Sergipe Órgão oficial dos Atos do Poder Executivo dêsse Estado da Federação Brasileira, recebemos os seguintes exemplares, nesse trimestre: Do Ano $\mathrm{n}^{\circ}$ XLVI -15.108 de 25-6-965; $N^{\circ} 15.109$ de 8-7-965 até 15.119 de $30-7-65 ; \mathrm{N}^{\circ} 15.119$ de $30-7-965 ; 15.122$ de $6-8-65$ e 15.129 de 20-8-65; $\mathrm{N}^{\mathrm{o}} 15.138$ de 13-9-65 até 15.144 de 24-9-65, da cidade de Aracaju, capital do Estado de Sergipe.

Experiente - Órgão da Universidade Rural do Estado de Minas Gerais, apresenta seu volume 5, de Março de 1965 , cujo $\mathrm{n}^{\circ}$ é 3 , «Estudos de Digestibilidade de Forragens Tro picais pelo Processo Convencional». Este boletim é publicado com intervalos irregulares, pelo Comité de Publicações da citada Universidade, tendo sua tiragem variável, a qual é dedicada a intercâmbio com outros órgãos de imprensa, bastando para isso, que a entidade inte- ressada nêle, dirija pedido à: Imprensa Universitária da Universidade Rural do Estado de Minas Gerais, cidade de Viçosa, Brasil.

El Fono - Publicación del Colegio de Abogados del Mexico. Temos em mãos, os volumes ns. 42 e 43 , referentes à cuarta época, senćo o de $n^{\circ} 42$ correspondente ao periodo de Julho a Setembro de 1963, e o 43 , correspondente a Outubro/Dezembro do mesmo ano, ambos editados no Distrito Federal do México. Conforme o próprio nome indica, trata-se de publicação exclusiva de assuntos juridicos, sob a direção da Comision Editora de la Barra Mexicana.

Guanabara Industrial - Esta revista é o órgão oficial do Centro Industrial do Rio de Janeiro e da Federação dás Indústrias do Estado da Guanabara. No volume de $\mathrm{n}^{\circ} 30 \mathrm{e}$ no de $n^{\circ} 31$, respectivamente, de Julho de 1965 e de Agôsto do mesmo ano, pertencentes ambos ao Ano II dessa publicação, aparecem várias reportagens a respeito de indústria, quer brasileira quer internacional; o exemplar de $\mathrm{n}^{\circ} 31$, apresenta em sua seção intitulada «Análise e Estudos Econômicos», um retrospecto semestral econômico-financeiro, que abrange o primeiro semestre do corrente ano.

I.D.O.R.T. - Revista do Instituto de Organização Racional do Trabalho. Esta é uma revista que cuida de assuntos de Organização e Produtividade, e o mencionado Instituto é órgão do Comité Nacional Brasileiro, que por sua vez, é filiado ao Conseil International de l'Organisation Scientifique (CIOS), que tem sede em Genebra. Temos em nosso poder, presentemente: Ns. 401/02, de Maio/Junho de 1965, e Ns. 403/04 de Julho/Agôsto de 1965, ambos do Ano XXXIV dessa publicação, editada no Estado Brasileiro de São Paulo.

Informaçốes do Uruguai - Boletim impresso na Embaixada do Brasil, no Uruguai, pelo Serviço de Propaganda e Expansão Comercial, fornece variadas noticias, assim como: de exportação e importação de mercadorias entre êsses dois paises, 
produção de produtos mercantis e agropecuários, informes sôbre custo de vida oriundos de dados estatistícos fornecidos pelo Ministério da Industria e Trabalho do Uruguai, incluindo-se previsão de tempo para periodo que comporta a quinzena do mês vindouro àquele ao qual compreende o respectivo boletim. Conosco se acham: Ano IV No 7 - julho de 1965; Ano IV N. 8 - Agôsto de 1965, editados pelo SEPRO de Montevideu, no Uruguai.

Inforformacion Juridica - Esta publicação ć editada pela Comision de Legislacion Extranjera do Ministério da Justicia da Espanha. O exemplar de ns. 262/3 do periodo Março/ Abril de 1965, apresenta o Código de Procedimiento Civil de Chile Tomo II - Libro tercero, que trata dos Juizes Especiais. O de ns. $264 / 5$, estuda a Constituição da Turquia.

Informe del Seminario de Las Naciones Unidas sobrle Programacion del Desarrollo Industrial - Esta publicação foi editada pelo Departamento de Assuntos Econômicos e Sociais da ONU, em espanhol. O seminário a que se refere o presente boletim, foi celebrado no Estado Brasileiro de São Paulo, de 4 a 15 de março de 1963.

Kriterion - Revista da Faculdade de Filosofia da Universidade de Minas Gerais, publica, sòmente, colaboração solicitada, atendendo ao vasto campo de filosofia, literatura, história, sociologia e demais assuntos dependentes ou relacionados a essas doutrinas. $N^{2} 63$ - Janeiro/Dezembro de 1965 , proveniente da cidade de Belo Horizonte, capital do Estado de Minas Gerais, Brasil.

Lioros de Portugal - Este é um boletim mensal ćo Prêmio Nacional dos Editores e Livreiros. Cuida sempre de apresentar obras mundialmente conhecidas, bem assim, biografias de autores e literatos famosos. Traz em sua capa, invariàvelmente, a fotografia de um escritor. Em nosso poder, atualmente, $\mathrm{o} \mathrm{n}^{\circ} 78$ de Junho de 1965 e o n $^{\circ} 79$ de Julho do mesmo ano, editados em Lisboa, Portugal.
Mensário Estatistico - $\mathrm{N}^{0} 167$ - de Maio de 1965 - Estado da Guanabara, Brasil. Publicação do Serviço de Estatistica Econômica e Financeira do Ministério da Fazenda, em que são apresentados levantamentos estatisticos a respeito de finanças públicas, comércio exterior e de cabotagem, e ainda, sôbre câmbio, moeda, produção, arrecadação e demais assuntos econômicos.

Methods of Hydrological Forecasting for the Utilization of Water Resources - A publicação de $\mathrm{n}^{\circ} 27$. proveniente das Nações Unidas, chegada a esta redação, contém conferências lidas no Seminário para Métodos de Previsão Hidrológica e da Utilização de Água. O seminário realizou-se em Bangkok, na Tailândia, entre 4 e 17 de agôsto de 1964.

Noticias de Portugal - Boletim semanal do Secretariado Nacional da Informação, expedido pelo Palácio Foz, em Lisboa, Portugal. Nêle săo noticiados, seminários, reuniões, congressos, solenidades em geral, ocorridas em qualquer ponto do território português. Temos conosco, presentemente, os seguintes exemplares:

Ano XIX - Ne 948, de 3 de julho de 1965 , até $N^{\circ} 952$, de 31 do mesmo mês e ano; Ns. 953, de 7 de agôsto de 1965, até $\mathrm{N}^{\circ} 956$ de 28-8-965; Ns. 957, de 4 de setembro de 1965 , até $\mathrm{N}^{\circ} 960$, de 25 do mesmo mês e ano.

Noticiero Bibliotecario Interamericano - Este é um boletim de publicação trimestral editado pela Biblioteca Colón - Departamento de Assuntos Culturais, da União Panamericana, situada em Washington 6, D.C. Cuida êle dos mais variados assuntos relacionados com a ciência da biblioteconomia. Temos os ns. 38 e 39 , ambos escritos em espanhol, e pertencentes, respectivamente, aos meses de Outubro/Dezembro de 1964 e a Janeiro/Março de 1965.

Paraná Econômico - Esta publicação, conforme seu próprio «slogan» indica, é o órgão de defesa dos interêsses da produção do Estado do Paraná, no Brasil. Ela é publicada 
pela Federação do Comércio do referido Estado, em colaboração com a Federação das Incúustrias do Estado do Paraná e com o Serviço Social do Comércio (SESC), e ainda mais, com o Serviço Nacional de Aprendizagem Comercial (SENAC). Do Ano XIII dessa publicação, temos os volumes $n^{9} 148$, do mês de Julho de 1965; e o de ns. $149 / 50$, referente aos meses de Agôsto/Setembro de 1965, editados na cidade de Curitiba, capital dêsse Estado Brasileiro.

Relatório de Blumenau - A presente publicação consiste do Relatório dos Negócios Administrativos do Municipio de Blumenau, referente ao ano de 1964, apresentado à Câmara Municipal, pelo Prefeito Hercilio Deeke. Contém farta ilustração através da qual se pode confrontar o bom andamento dos trabalhos ali realizados $e$ as atividades que tem desempenhado, em prol daquela região, a Prefeitura local dêsse municipio situado no Estado Brasileiro de Santa Catarina.

Revista de Administração Municipal Esta é uma publicação bimestral do Instituto Bras leiro de Administração Municipal, outrora, denominada Noticias Municipais. Recebemos dêsse mesmo Instituto, o Relatório das Atividades do Exercicio de 1964, que termina falancio das Perspectivas daquele Instituto para o futuro, em virtude da constante renovação que vem se verificando nos métodos e processos da administração municipal brasileira, que exigirăo dêsse Instituto uma atuação cada vez maior. Recebemos, agora, o $\mathrm{n}^{\circ} 70$ de Maio/Junho de 1965, e o n 71 de Julho/Agôsto do mesmo ano, cujo órgão é localizado no Estado da Guanabara, no Brasil.

Revista de Administracion Pública Esta revista é publicada semestralmente pela Escola de Administracion Publica do Colegio de Ciencias Sociales de la Univiersidad de Puerto Rico, dedicando suas páginas inteiramente ao trato de assuntos exclusivos de ciência da administração. Comporta ainda uma seção de livros e publicações recen- tes editadas naquele pais, e dela recebemos o $n^{9} 1$ - Vol. II - de junho de 1965.

Revista Bancária Brasileira - Do Ano 33, cujo $\mathrm{n}^{\circ}$ é 388 , de 30 de abril de 1965, é o exemplar dessa revista que temos em mãos, a qual tem por programa registrar e arquivar em suas páginas, tudo o que se relacione com a vida bancária, econômica e financeira do Pais, como um órgão técnico especializado neste assunto. E uma publicação mensal. distribuida nos Estados do Brasil, órgãos de classe bancária comércio e meios financeiros. Tem ela ampla circulação em todo o Pais e no Exterior, com correspondentes e representantes em todos os Estados e no Estrangeiro. Edita balancetes bancários, regularmente, e matéria atinente a bancos, em geral.

Revista de Ciencias Sociales - Esta revista se publica trimestralmente em março, junho, setembro e dezembro, em Rio Piedras Puerto Rico. Compete sua edição ao Colegio de Ciencias Sociales de la Universidad de Puerto Rico. Recebemos o $\mathrm{n}^{\circ} 1$ - Volume IX de Março de 1965.

Revista Danesa - Recebemos o $\mathrm{n}^{2} 18$ dêsse ano, desta revista que é publicada pelo Serviço de Imprensa e Informação do Real Ministério de Relações Exteriores da Dinamarca. Editada na cidade de Christians. borg, em Copenhague K.y Soren Dyssegaard, vem escrita em espanhol e seus principais artigos e reportagens versam sôbre indústria $e$ comércio daneses.

Revista Ecuatoriana de Higiene y $\mathrm{Me}$ dicinal Tropical _- Esta revista é órgão oficial do Instituto Nacional de Higiene «Leopoldo Izquieta Perez», e é editada em Guayaquil, no Ecuador, país amazônico. São convidados a prestar colaboração à referida revista, todos os médicos, engenheiros sanitaristas químicos, dentistas, enfermeiras sanitaristas, e em geral, todas as pessoas que se interessam ou se dedicam aos problemas de higiene, de medicina tropical, sanidade, bem como, maté- 
rias afins, cujos trabalhos, uma vez apresentados serão publicados sem maiores formalidades, além da simples aprovação do Comité de $\mathrm{Re}$ dação, existente na mesma. Presentemente, conosco, o $\mathrm{n}^{\circ} 1$ - volume 22 de janeiro/abril de 1965, de Guayaquil, Ecuador.

Revista da Escola de Minas - Esta revista é publicada pelos alunos e reconhecida pelo Diretório Acadêmico da Escola de Minas de Ouro Prêto, cidade-monumento do Estado Brasileiro de Minas Gerais, sendo composta e impressa na tipografia da própria Escola. Dedicase ela a apresentar artigos que versem, preponderantemente sôbre Geologia, Engenharia de Mnas, Engenharia Civil, Engenharia Metalúrgica e matérias correlatas a tais assuntos, conforme o que apresenta o $\mathrm{n}^{\circ} 2$ - volume XXIV - de Julho de 1965.

Revista de Finanças públicas - Editada pelo Conselho Técnico de Economia e Finanças do Ministério da Fazenda dos Estados Unidos do Brasil. Trata exclusivamente de finanças, conforme seu nome indica, bem assim, de economia, contabilidade, moeda, orçamento, câmbio, comércio exterior e interno, crédito em geral, cuidando, enfim, de tôdas as matérias correlatas à sua finalidade. $O$ presente $n^{\circ} 232$ do Ano XXV, referente a fevereiro de 1965, proveniente do Estado da Guanabara, apresenta um Indice alfabético remissivo por assunto, da Lei $\mathrm{n}^{\circ} 4.320$, de 17-3-64, a qual estabelece normas gerais de Direito Financeiro, aplicáveis aos Orçamentos e Balanços Públicos. O Indice em questão foi elaborado na Secretaria do citado Conselho, e tem por objetivo, simplificar as consultas à referida Lei, ressaltando o dito órgão, que a nomenclatura da discriminação baseou-se no próprio texto dessa legislação.

Revista de Hacienda - A Direção e Redação desta revista, ficam a cargo da «Comisión de Investigaciones Financieras y Económicas». E ela um órgão do Ministério da Fazenda da República da Venezuela. Apresentam suas páginas resumos dos movimentos fiscal, portuário, orçamentário, de receita e despesa públicas daquele pais, entre outros assuntos mais. Temos conosco, do Ano XXVII, o $\mathrm{n}^{\circ} 47$ de Outubro/ Dezembro de 1963.

Revista de Intendência da Aetonáutica. Esta revista é uma publicação regulamentar da Diretoria de Intenciência de Aeronáutica, na qual vem esclarecido, entretanto, que quaisquer conceitos que forem reproduzidos por seu intermédio, sôbre regulamentos, ordens, avisos ou leis, não devem ser invocados no processamento normal burocrático, apenas pelo fato de nela terem vindo a lume. Chegados à nossa redação, do Ano XVI, o n ${ }^{\circ} 161$, de Janeiro de 1965 e o n 162 de Fevereiro do mesmo ano, oriundos do Estado dá Guanabara.

Revista do IRB - Esta é uma publicação bimestral editada pelo Serviço de Relações Públicas do Instituto de Resseguros do Brasil. Trata ela dos assuntos nacionais e internacionais de seguro e resseguro. Possuimos, presentemente, do Ano XXVI, o $\mathrm{n}^{\circ} 151$ referente a Junho/Julho de 1965, e o de $n^{\circ} 152$. do periodo Agôsto/Setembro do mesmo ano.

Revista do Sindicato Nacional da Indústria do Cimento - Do Ano XII, e o $\mathrm{n}^{\circ} 139$, de Maio dêste ano, editado no Estado da Guanabara, desta revista que já se denominou, anteriormente, Boletim Mensal do SNIC. Ela se dedica a tratar todos os assuntos relacionados com a indústria do cimento, recebendo, inclusive publicidade das firmas especializadas nesse ramo. Esse órgão destaca, também, uma parte para a divulgação de leis, reuniões e outros assuntos de grande importância geral. Recebemos, ainda, um Indice Geral da matéria publicada em 1964, organizado pela indicação numérica de acôrdo com a Revista, e também, de acôrdo com o assunto.

Reure Internationale des Sciences Administratives - Revue de l'Administration de la Cooperation Technique et de l'Assistance Economi- 
que du Institut International des Sciences Administratives, en Belgique, Bruxelles. Rue de la Charité 25. Recebemos, presente: $\mathrm{N}^{\circ} 4$ de 1964 - Ano XXX; e $N^{\circ} 1$ de 1965 - Ano XXXI.

Strala Internacional - Esta revista apa rece mensalmente em sete linguas, que são: português, alemão, árabe, espanhol, finlandês, francês, inglês, e é editada na Alemanha. Ela é vendida em qualquer banca de jornal e assinaturas da mesma, podem ser pedidas em qualquer dessas linguas. E enviada ao Brasil, uma edição luso-brasileira. Dela, temos, presentemente: $\mathrm{N}^{\circ} 7$ - de Julho de 1965; $\mathrm{N}^{\circ} 8$ - de Agôsto de 1965 e No 9 - de Setembro do mesmo ano, editados em Frankfurt.

Sintese Politica, Econômica le Social Este órgão oficial do Instituto de Estudos Políticos e Sociais da P.U.C., é de publicação trimestral. Em nota de rodapé esta revista informa que aquele Instituto mantém uma Escola de Sociologia e Politica, destinada a formar especialistas nestas disciplinas, e que também realiza pesquisas sociológicas de âmbito local, regional e na cional, colocando ainda, ao alcance do público, grandes obras nacionais e estrangeiras. Temos, re centemente, em nossa redação o $n^{\circ} 26$, de abril/junho de 1965, editado no Estado da Guanabara, no Brasil.

Trade And Devlelopment - Publicação das Nações Unnidas, que trata de Comércio e seu desenvolvimento. A parte I apresenta meticulosos conceitos sôbre a expansão comercial, de acôrdo com os agrupamentos regionais. Contém mais o referido livro, um número de monografias sôbre a expansão no comércio in- ternacional, visando o desenvolvimento econômico, de acôrdo com os agrupamentos regionais. Há uns artigos que tratam de paises que não têm saída para o mar; discute ainda o mesmo livro, a Resolução de Niamery, na Conferência ças Nações Unidas, a respeito de comércio e seu desenvolvimento na África. Registra também, «A Carta de Alta Gracia», pela Organização dos Estados Americanos. Procura esta obra esclarecer quais são os problemas dos paises que têm sistemas sociais e econômicos diferentes. Trata, finalmente, do assunto decorrentes do comércio no passado, dando previsões sôbre o comércio entre paises com suas eco nomias centralizadas, e, outrossim, sôbre outros com sua economia já em desenvolvimento.

Trade And Development - Trade in Manufactures - Publicação das Nações Unidas que cuida de Indústrias. Contém êste volume, estudos realizados e debatidos nas Conferencias das Nações Unidas, em tôrno de Comércio e seu desenvolvimento nos paises subdesenvolvidos, e analisa êsses problemas. Ventila o assunto dos paises que exportam mercadorias industriais, por êles produzidas, e discute, também a procura de tais mercadorias nos paises desenvolvidos. Indica métodos destinados a incrementar a exportação de produtos semi-fabricados, como também, a eliminação de carreiras, e ainda, como conseguir convênios com preferência.

World Energy Supplies - Statistical Papers - 1960-1963 — Nações Unidas. Essa publicação explica as bases da produção de carvão, de petróleo, de gases e de eletricidade, bem como, a produção e consumo de energia. 